\title{
MAPAS DE CONHECIMENTO E MEMORIZAÇÃO PERMANENTE DE CONHECIMENTO E APRENDIZADO: UMA PROPOSTA DE NOVAS FERRAMENTAS NO AUXÍLIO DO RESGATE DO IDOSO À AUTOESTIMA E CIDADANIA
}

\section{KNOWLEDGE MAPS AND PERMANET LEARNING AND KNOWLEDGE MEMORIZATION: A PROPOSAL OF NEW TOOLS TO AID RECOVERY OF ELDERLY SELF-ESTEEM AND CITIZENSHIP}

RESUMO: Este artigo apresenta uma proposta de um conjunto de ferramentas voltadas para o trabalho de resgate da cidadania de pessoas idosas por meio da recuperação da autoestima e inserção do idoso ao ambiente familiar e social. Essa ferramenta: Mapas de Conhecimento, tem como objetivo auxiliar o idoso na efetivação do processo de resgate da memória, principalmente a memória recente. Ao longo da vida, o idoso vai acumulando conhecimentos e técnicas de manipulação mecânica, matemática e lógica do meio onde atuou. Por outro lado, o hemisfério direito, o qual é responsável pela abstração, pela criatividade, arte e sentimentos, fica menos sobrecarregado e com grande potencial para aprendizado e memorização. Diante desse cenário, as ferramentas propostas, e originais, constituídas por um Mapa de Conhecimento (o qual possui um raio de conhecimento e uma área de ignorância) e uma técnica de memorização efetiva e permanente, denominada por Memorização Permanente de Aprendizado $2^{n}$, vêm contribuir no sentido de integrar os dois hemisférios para efetivação de todos os processos envolvendo raciocínio e memorização. As ferramentas propostas, e amplamente testadas, utilizam uma regra temporal efetiva de reforço da informação que se quer perpetuar, a qual, agregada a outra estratégia e recurso visual, faz com que os hemisférios direito e esquerdo do cérebro trabalhem em conjunto no armazenamento e resgate da informação. Este trabalho contribui na sugestão de se utilizar as ferramentas propostas, as quais, se associadas às técnicas e metodologias tradicionais aplicadas à memorização e aprendizado dos idosos, conforme experiência obtida pela equipe desta pesquisa, podem levar os cuidadores dos idosos a atingirem resultados satisfatórios no resgate do idoso à cidadania.

Palavras-chave: idosos; mapas de conhecimento; memorização; autoestima; cidadania.

ABSTRACT: This paper presents a proposed set of tools with the goal of helping elderly people through the recovery of self-esteem and inclusion of the elderly into family and social environment. This tool, named Knowledge Maps, aims to assist elderly people to effectively recover memories, mainly the recent ones. Throughout life, the elderly will accumulate knowledge and techniques of mechanical, mathematical and logical manipulation of the environment in which they operate, which increasingly overloads the left hemisphere of the brain with various actions, both mechanical and processes that require mathematical and local reasoning. On the other side, the right hemisphere of the brain, which is responsible for abstraction, creativity, and music is less overloaded. Given this scenario, the proposed tool, consisting of a Map of Knowledge and Ignorance Area, and a tool called Permanent Learning $2^{n}$ will contribute to the possibility to integrate the two hemispheres of the brain for the execution of all processes involving memorizing and reasoning. The proposed tools, which were extensively tested, use an effective temporal rule to reinforce information to perpetuate memory, which added to another

\footnotetext{
${ }^{1}$ Doutor em Engenharia Elétrica - Universidade Federal de Uberlândia - UFU e Professor Efetivo da Universidade Estadual de Mato Grosso do Sul - UEMS .E-mail: rubens@comp.uems.br.

${ }^{2}$ Doutora em Engenharia Elétrica - UFU e Professora do Conservatório Estadual de Música e Centro Interescolar de Artes Raul Belém - CEMARB. E-mail: fo_sandralima@hotmail.com.

${ }^{3}$ Mestre em Engenharia Elétrica - UFU e Programador da KN Music Center. E-mail: hcjcamargo@gmail.com.

${ }^{4}$ Doutor em Engenharia Elétrica - Universidade de São Paulo - USP e Professor Adjunto da UFU. E-mail: vieira@ufu.br.
} 
strategy and visual resource make the right and the left hemisphere of the brain work together in the storage and retrieval of information. The contribution of this work is the suggestion of using the proposed tools, which when associated with traditional techniques and methodologies applied to learning and memorization for the elderly, as experience obtained by this research team, can lead the caretakers of the elderly persons to achieve satisfactory results in the recovery of citizenship.

Keywords: elderly persons; knowledge maps; memorization; self-esteem; citizenship.

\section{INTRODUÇÃO}

A vida média da maioria dos povos, e - Brasil não é exceção, tem aumentado significativamente. $\mathrm{Em}$ alguns desses países, os índices desse incremento de vida ocorre em maior proporção em relação a outros. Segundo a Organização Mundial de Saúde (WORLD HEALTH ORGANIZATION, 2013), o Brasil apresenta uma expectativa de vida acima dos 70 anos de idade, o que fará com que, muito em breve, seja uma nação de longevos (VERA, 2003). Essa expectativa cresce a cada censo realizado desde então.

Infelizmente, 0 acréscimo de quantidade de anos ao idoso não é acompanhado do mesmo acréscimo em qualidade de vida. Percebe-se, em todas as faixas sociais, a discriminação para com os idosos, principalmente quando tentam voltar ao mercado produtivo. Discriminação e descasos são frequentes para com os idosos, mesmo com tantas leis que os favorecem e com a atuação de entidades sociais que se preocupam, reivindicam e lutam pelos seus direitos.

Segundo Caldas e Saldanha (2004), um dos problemas que merece a atenção diz respeito à necessidade de se garantir as condições que propiciem o envelhecimento com dignidade. Apesar das leis e daquelas pessoas que simpatizam com uma melhor qualidade de vida para os idosos, estes, em boa parte, ainda experimentam uma carência nessa fase.
Segundo Sarti (1993), a família tornase o centro básico de convivência do idoso, trazendo consigo os elementos básicos da vida, e deixando de lado o convívio social e profissional do idoso e, dessa forma, todo o relacionamento do idoso passa a ser praticamente exercido com parentes.

É comum, entre os parentes, destacarse um que assume as atribuições de cuidador (acompanhante) principal do idoso, assim como assume tarefas de cuidados diários, atendendo às necessidades do idoso e responsabilizando-se por elas. Este trabalho busca trazer e apresentar novas técnicas e ferramentas que venham dar suporte ao cuidador para que o idoso possa se reintegrar tanto familiarmente quanto na sociedade.

O ambiente ao qual o idoso está inserido possui papel importante no processo de resgate à cidadania. É primordial que esse ambiente apresente as condições mínimas e necessárias para que as lembranças trabalhadas sejam resgatadas de forma eficiente e em curto prazo, já que, para os idosos, o tempo é um bem muito precioso.

Em relação ao ambiente em que se encontra uma pessoa submetida a um processo de aprendizagem, vale ressaltar uma das pesquisas de McLuhan (1967) sobre $\mathrm{o}$ meio onde $\mathrm{o}$ aprendizado e a informação a ser resgatada e memorizada estão contextualizados. Por meio dessa pesquisa, é possível perceber que cada tipo 
de estudo ou trabalho está diretamente relacionado com o meio físico no qual o processo está sendo efetivado.

McLuhan define os meios como frio e quente, onde os meios quentes são ricos em informações e ruídos, o que, no caso dos idosos, o excesso de informações e ruídos pode causar dispersão do foco do que se deseja ensinar ao idoso. Já nos meios frios, com baixo ruído, fica mais fácil focar um determinado assunto, principalmente ao se utilizar as ferramentas propostas neste trabalho. Entenda-se como ruído, tudo o que não é informação, tudo que concorre com a informação. Desta forma, no meio onde se vão aplicar as ferramentas propostas nesta pesquisa, movimentação periférica e assuntos periféricos, enfim, tudo que estiver fora do contexto da informação deve ser evitado para tornar o meio menos quente possível.

Assim, ao se trabalhar o resgate e memorização de informações com os idosos, deve-se realizá-los com somente uma atividade por vez, evitando desta forma, o uso de um conjunto de atividades paralelas. Estudos feitos por Miller e Seger (2010) provam que realmente pouco ou nada se aprende com a inserção de música, animações e outros recursos que tornam o meio mais quente. Este tipo de meio dificulta atividades cognitivas, sendo adequado preferencialmente onde se busca o treino de habilidades motoras e a melhora por meio de jogos.

A teoria sobre mapas mentais (BUZAN; BUZAN, 1996) explica o motivo de um gráfico ou uma figura ficar mais tempo gravada na memória do que um texto. A partir deste ponto, os mapas mentais acabam funcionando não só porque o lado direito do cérebro está menos sobrecarregado, mas sim devido aos textos serem processados sequencialmente pelo cérebro, enquanto as imagens são processadas em paralelo, como um todo, utilizando mais o hemisfério direito do cérebro, o qual possui menos sobrecarga nas tarefas diárias do que o hemisfério esquerdo.

Dessa forma, uma informação memorizada também pelo hemisfério direito do cérebro, se liga a várias outras armazenadas também pelo hemisfério esquerdo, disponibilizando um conjunto maior de informações associativas ou complementares que auxiliam no resgate e memorização de outras informações. $O$ ato de se lembrar de uma imagem é mais rápido e mais simples para o cérebro processar, do que 0 ato de se buscar uma determinada informação textual (memória semântica) (IZQUIERDO, 2010).

Portanto, de tais autores e de experimentos realizados nesta pesquisa, o processo de extração de conteúdo, mesmo textual, dentro de um gráfico ou figura, quando realizado pelo lado esquerdo do cérebro junto com o lado direito do cérebro, é um processo com mais chances de sucesso (intuição e lógica trabalhando em conjunto) do que apenas o uso do hemisfério esquerdo.

As ferramentas propostas neste trabalho denominadas Mapas de Conhecimento e Ferramenta de Memorização Permanente de Aprendizado $2^{\text {n }}$ oferecem uma solução na busca da sedimentação e memorização progressiva dos assuntos que se deseja resgatar (lembrar).

Uma vez que 0 processo de recuperação de memória tenha obtido êxito, torna-se importante identificar uma forma de 
se fixar o conhecimento recuperado. Diante deste desafio, este trabalho, após várias experimentações, concluiu por uma metodologia de fixação de conteúdo, utilizando o que foi denominado por "Reforço $2^{\text {n". }}$. Essa relação de um reforço conceitual em intervalos de tempo, em dias, de $2^{n}$, garante que as lembranças recuperadas ficarão memorizadas pelo idoso eficazmente desde que os intervalos de recordação sejam mantidos.

Assim sendo, este trabalho tem como objetivo fornecer um conjunto de técnicas e ferramentas que permitam a um cuidador aplicá-las ao idoso, de forma que este possa reter informações e conceitos enquanto saúde mental tiver, facilitando o resgate à autoestima, a reintegração à família, à sociedade e, por fim, quando possível, até mesmo ao mercado de trabalho.

Este trabalho está dividido em seções, sendo que a seção 2 apresenta um modelo de mapeamento entre categorias utilizando funtores; a seção 3 apresenta uma ferramenta de aprendizado utilizando Mapas de Conhecimento; a seção 4 apresenta uma ferramenta de memorização utilizando o conceito de reforço $2^{\text {n}}$; a seção 5 apresenta um estudo de caso com idosos utilizando as ferramentas propostas neste trabalho; a seção 6 apresenta os resultados obtidos e, por fim, a seção 7 apresenta as conclusões a que se chegou neste estudo.

\section{RESGATE DO IDOSO POR MEIO DE CATEGORIAS}

Da teoria de funtores (ASPERTI; LONGO, 1991), tem-se que, para se implementar um funtor entre duas categorias, deve-se cumprir a exigência mínima de que as duas categorias possuem os mesmos objetos e morfismos equivalentes. O funtor é a entidade matemática que garante que, ao ser estabelecido, o processo de aprendizado torna-se propício a ocorrer. Assim, no processo de resgate do idoso à família, à sociedade e ao mercado de trabalho, destacam-se duas categorias, uma representada por uma pessoa acompanhante (cuidador) e outra por um idoso, respectivamente, sendo que essas categorias devem possuir os conceitos e ferramentas básicas (similares ou equivalentes) necessárias para 0 resgate e memorização dos conhecimentos que se quer dotar ao idoso, isto é, deve-se estabelecer, por meio das categorias, uma comunicação e uma identificação entre o idoso e o cuidador.

Dessa forma, determinados conhecimentos (estabelecidos pelo funtor) serão trabalhados de forma a resgatar, progressivamente, as lembranças e conceitos (aqui chamados de objetos) existentes na memória do idoso, bem como a manipulação e domínio (aqui chamados de morfismos) desses conhecimentos básicos. Se na categoria do idoso faltar algum objeto (ter alguma lembrança inventada ou que não fez parte da vida do idoso) ou um morfismo (saber trabalhar essa lembrança), a aplicação do funtor (resgate das lembranças) fracassará.

Um funtor, de uma forma mais simplificada, representa a viabilidade e a forma com que o cuidador irá interagir com o idoso para poder resgatar os seus conhecimentos e lembranças. Esse mapeamento entre o idoso e cuidador, no caso o funtor, é o que, uma vez estabelecido, permite que o que se busca resgatar vai obter o sucesso desejado. 
O cuidador (categoria cuidador), antes de iniciar o resgate, deve dotar o idoso (a categoria idoso) dos objetos e morfismos fundamentais para o estabelecimento do funtor, o que o levará a se integrar, progressivamente, primeiro à família, depois à sociedade e, finalmente, ao mercado de trabalho.

A Fig. 1 apresenta um diagrama composto por duas categorias, de forma a se permitir a identificação dos seus componentes teóricos. Destacam-se, nesse diagrama, as categorias ( $C$ e $D)$, os funtores (F1), os objetos(a e b) e os morfismos $\left(F_{1 \text { Mor }}\right)$, nos quais cada conteúdo (objeto) presente na categoria $\mathrm{C}$ (Cuidador) representa os conhecimentos e lembranças necessárias a se resgatar junto à categoria Idoso. Cada morfismo ( $\left.F_{1 \mathrm{Mor}}\right)$, ligando a categoria do Cuidador (C) à do Idoso (Categoria D), representa a forma ou o método de se trabalhar esse resgate. $\varlimsup_{1}$

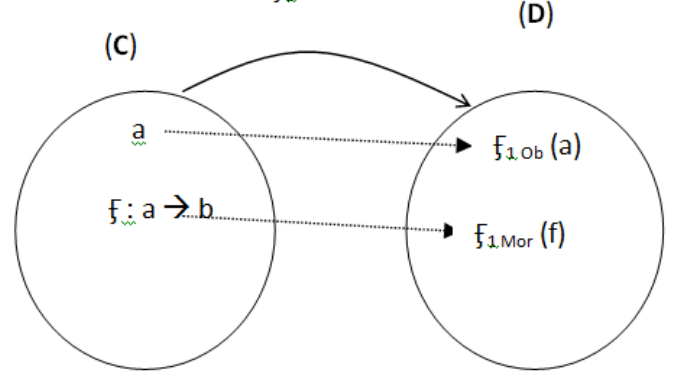

Fig. 1 - Diagrama de Categorias, Funtores, Objetos e Morfismos.

Dessa forma, só são levados da categoria Cuidador $(\mathrm{C})$ à categoria Idoso (D) aqueles conceitos e lembranças que realmente tenham alguma relação com 0 objetivo de lembrança estipulado, bem como, os métodos que sejam mais adequados ou aderentes ao resgate dos conceitos. Um exemplo prático que aborda o diagrama apresentado na Fig. 1 pode ser visto na Fig. 2. Nessa Fig. 2, tem-se um diagrama com os componentes pertencentes a uma integração do idoso à família.

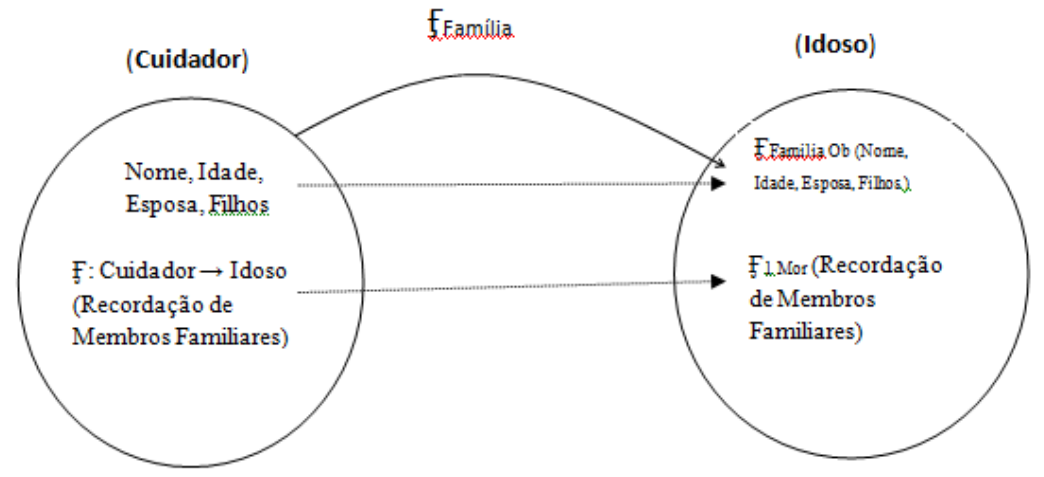

Fig. 2 - Mapeamento dos objetos e morfismos por meio de funtores relacionados à família.

O foco do resgate nesse diagrama está na recordação de conhecimentos 
relativos ao idoso e aos membros familiares. Inicia-se pela recordação do próprio nome, idade, quem é a esposa desse idoso, quem são os seus filhos, e outros parentescos mais próximos e que fazem parte do cotidiano do idoso. No diagrama da Fig. 2, é apresentado um mapeamento dos objetos (termos e conteúdos) necessários ao resgate do idoso. Nesse mapeamento, indicados pelo funtor "Família", os objetos são discriminados por (Nome, Idade, Esposa e Filhos). O morfismo é discriminado por (Recordação de Membros Familiares) e o funtor é representado por ( $\mathrm{F}_{\text {Familia }}$ ).

Com base na Fig. 2, uma pergunta fundamental surge.

- Como iniciar o processo de resgate dos conhecimentos?

As respostas a esse novo questionamento são enumeradas a seguir:

1. Deve-se restringir ao máximo ao contexto do idoso. Durante o processo de resgate, os exemplos elaborados devem pertencer ao cotidiano da pessoa. Em hipótese alguma se deve fornecer exemplos fantasiosos (mesmo que bem intencionados e lúdicos) que não estejam relacionados às atividades realmente já exercidas pelo idoso.

2. Após solucionar o problema do item 1, deve-se iniciar o resgate das lembranças pelo estabelecimento de funtores com conhecimentos pontuais que exijam da categoria Idoso a menor quantidade possível de objetos e morfismos.

3. Deve-se evitar o excesso de inserção de objetos e morfismos que possam vir a confundir o idoso. $O$ excesso de informação que foge ao foco do que se quer recordar torna o meio mais quente, tirando a atenção do idoso do que se deseja transmitir, além de bloquear o processo cognitivo de memorização. Essa atitude causaria uma tentativa, por parte do idoso, de tentar anexar tais informações à categoria do Idoso, tornando mais complexo o estabelecimento do funtor e podendo levar o processo ao fracasso. Assim, os excessos de objetos e morfismos são tão indesejáveis quanto a sua falta.

Dessa forma, uma vez identificadas as subcategorias, os objetos e morfismos essenciais e necessários nas categorias Cuidador e Idoso, propõe-se, a seguir, uma ferramenta singular, original, capaz de dotar ao idoso, de uma forma gradativa e visualmente estimulante, os conhecimentos a serem recordados.

\section{MAPAS DE CONHECIMENTO: RAIO DO CONHECIMENTO E ÁREA DA IGNORÂNCIA}

A ferramenta "raio do conhecimento e área da ignorância" (Mapa de Conhecimento) é utilizada, no contexto deste artigo, para dotar os idosos das recordações mínimas, necessárias e essenciais ao resgate do idoso ao meio familiar, social e ao mercado de trabalho.

O ideal, nesse contexto, seria começar a recordar todas as lembranças do idoso, desde a mais tenra idade, mas isso é impraticável. Porém, deve-se ater àquilo que se quer recordar, com um objetivo e com um grau de conhecimento e maturidade bem definidos. O raio do conhecimento e área da ignorância está fundamentado da seguinte forma:

1) Tem-se um círculo em que o raio representa o conhecimento que se tem ou se quer recordar, e a área representa a ignorância de conceitos e definições que esse raio desperta no idoso. Assim, por meio de experimentações, concluiu-se que tanto a 
área da ignorância, quanto a área do círculo cresce proporcional ao quadrado do raio do conhecimento que se deseja recordar. Dessa forma, é fundamental que a primeira recordação, isto é, o primeiro conhecimento a ser estabelecido ao idoso tenha o menor raio possível, de tal forma que se possa, em curto prazo, eliminar toda a ignorância associada a esse conhecimento. Um exemplo de raio mínimo seria iniciar a lembrança pela recordação do próprio nome do idoso, seguido de quem é ele, quem foi, o que fazia, da importância que exercia na família e sociedade.

2) É fundamental iniciar o processo de reintegração do idoso pelo menor raio possível, o "raio inicial das lembranças", o qual é representado pelas lembranças consolidadas citadas no item 1 desta numeração. Esse raio é aquele dentro da área do círculo em que a área inicial da ignorância não apresenta dúvidas ou informações errôneas. A partir dessa base, pode-se afirmar que novas recordações poderão ser reativadas ao idoso. Nessa teoria dos Mapas de Conhecimento, as ignorâncias ou dúvidas a serem esclarecidas são apresentadas na área do círculo, internamente, por interrogações indexadas, as quais não existem na área inicial da ignorância, conforme mostrado na Fig. 3.

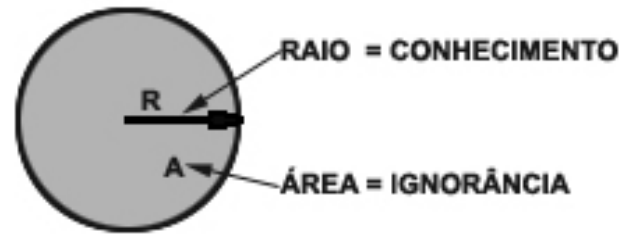

Fig. 3 - raio do conhecimento e área da ignorância.

3) O uso dos Mapas de Conhecimento para dotar aos idosos de estratégias visuais que garantam a assimilação das lembranças trabalhadas prossegue, identificando o menor raio de lembranças (conhecimento) (dR) que deve ser proposto ou trabalhado com o idoso, de tal forma a gerar o menor acréscimo $(\mathrm{dA})$ na área de sua ignorância, conforme Fig. 4.

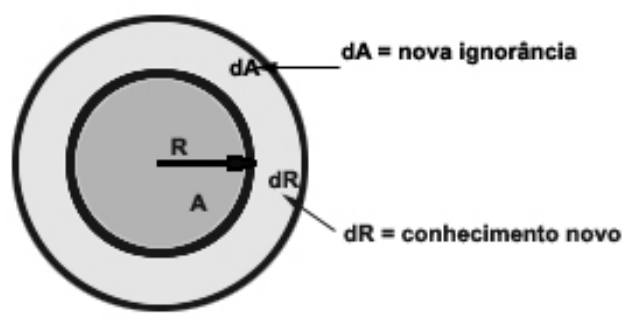

Fig. 4 - Nova lembrança implica em nova área de ignorância.

4) Dessa forma, cada módulo (lembrança nova) deve apresentar um incremento controlado da lembrança a ser recordada.

5) A partir do raio mínimo de lembranças (ou conhecimentos), as lembranças seguintes partem dessas lembranças iniciais (aquilo que o idoso ainda consegue se lembrar). Essa lembrança inicial, no Mapa de Conhecimento, denominada por pré-lembrança, fará parte da área das lembranças iniciais, ou seja, toda área de ignorância, em uma nova etapa, é transformada em área de lembrança pré-recordada e simbolizada no mapa por um sinal de exclamação indexado.

Toma-se como exemplo um mapeamento estabelecido entre um cuidador e um idoso com o objetivo de se recordar os membros da família, conforme mostrado na Fig. 2.

Uma vez identificados quais serão os membros familiares que serão recordados e como será feito esse resgate, pode-se elaborar o Mapa de Conhecimento, 
composto pelo raio de conhecimento e a área da ignorância, conforme pode ser visto na Fig. 5.

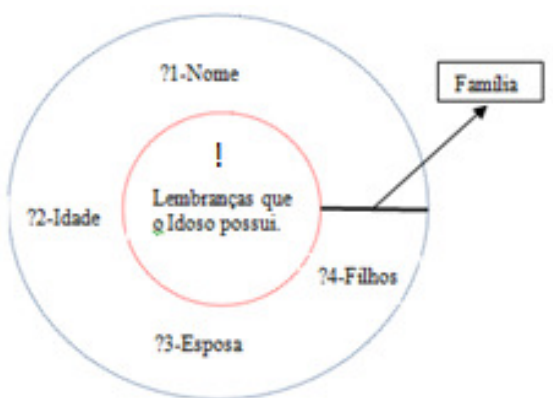

Fig. 5 - raio do conhecimento = Lembrança da família.

O processo de padronização dessa estrutura inicia-se colocando uma interrogação com 0 nome foco da lembrança, sem se preocupar em conceituála, bastando apenas saber que ela existe. Esse mapa ou diagrama tem como objetivo ativar e despertar a participação do lado direito do cérebro no processo de memorização das lembranças.

Como o lado direito é geralmente menos atarefado do que o esquerdo, a memorização de imagens é mais duradoura do que a de textos, o que facilitará o resgate das informações contidas nas imagens (por imagens pode-se supor, nesse contexto, a disposição de fotografias de pessoas ou locais que representem as lembranças que se quer resgatar). É importante, sempre que possível, utilizar fotografias que ajudem no processo de resgate das lembranças que serão trabalhadas junto ao idoso.

A partir da estrutura do raio do conhecimento e área da ignorância, pode-se complementar essa estrutura com a formatação de um texto que permita associar a todas as lembranças presentes na Fig. 5, uma explicação sobre os conhecimentos já sedimentados pelo idoso. Assim, esse texto passa a apresentar as recordações que 0 idoso ainda possui (retém), e uma explicação sobre aquelas lembranças que já estão perdidas, mas que se deseja recordá-las, tornando efetiva a participação da parte cognitiva do lado esquerdo do cérebro. A Fig. 6 exemplifica um tipo de formatação textual das lembranças presentes na Fig. 5.

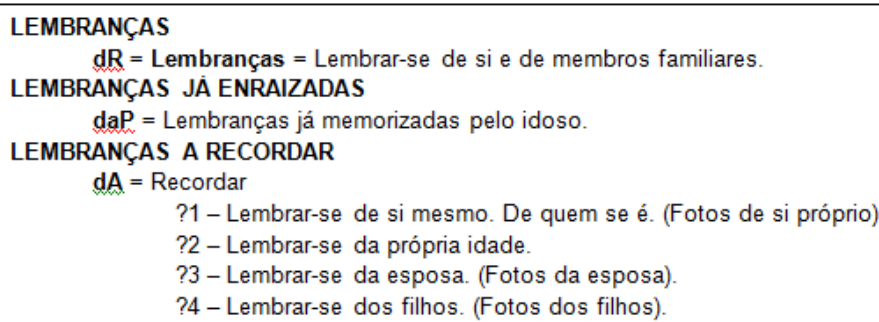

Fig. 6 - Formatação textual do raio do conhecimento e da área da ignorância.

Observe a estrutura da Fig. 6. Ela não só formaliza a formatação mas permite ao cuidador do idoso que está elaborando o Mapa de Conhecimento verificar se este foi montado corretamente.

Uma vez conhecidas e recordadas todas as dúvidas do mapa montado, pode- se montar o Mapa de Conhecimento de um novo conjunto de recordações que terá, como pré-lembranças, as lembranças já adquiridas. É fundamental que um conjunto novo de lembranças tenha algum relacionamento com as lembranças já enraizadas, para que se possa criar um vínculo entre elas. 
Como exemplo, tem-se um segundo relações familiares do idoso, conforme pode funtor com o objetivo de se explorar as ser visto na Fig. 7.

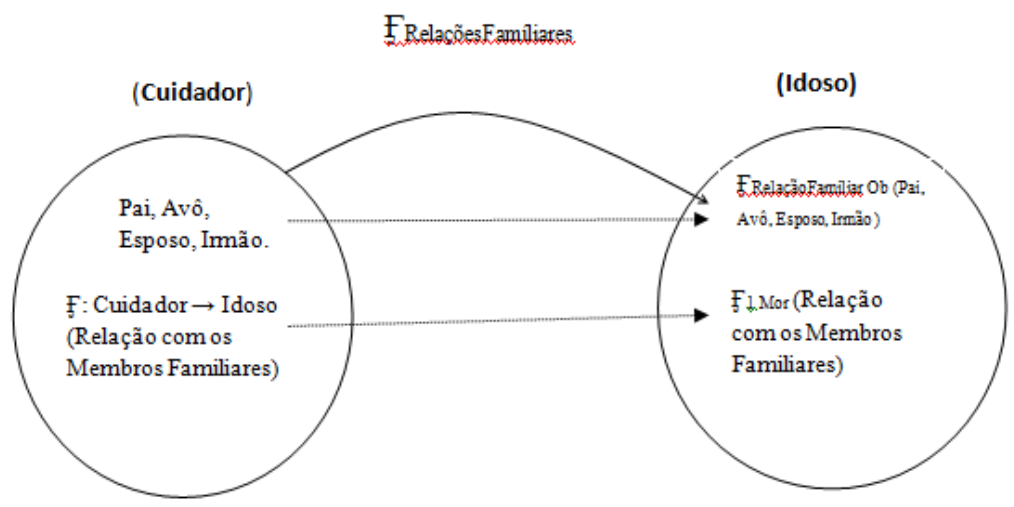

Fig. 7 - Mapeamento mostrando a relação familiar do idoso com os demais membros da família.

Por meio da Fig. 7, é possível perceber o avanço gradativo na quantidade de objetos (informações) que serão novamente recordados ao idoso. Em um primeiro momento, tratou-se de resgatar a autoestima do idoso, mostrando quem ele é, sua idade e outras informações referentes ao seu autorreconhecimento. Nesse segundo mapeamento, o foco passa a ser a relação existente entre o idoso e os demais membros familiares próximos, como, por exemplo, esposa, filhos, netos e irmãos.

A partir da Fig. 7, pode-se montar 0 Mapa de Conhecimento com essas novas informações. A Fig. 8 apresenta a formatação desse Mapa de Conhecimento.

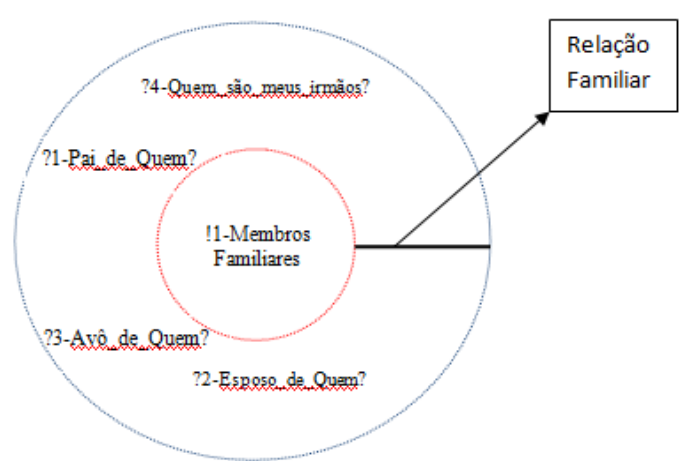

Fig. 8 - raio do conhecimento e área da ignorância - Relações Familiares.
A Fig. 8 apresenta 0 raio do conhecimento e a área da ignorância quando aplicados ao processo de recordação da relação familiar vivida pelo idoso. Nessa etapa, os questionamentos trabalhados focam-se na recordação de laços e relações familiares, com o objetivo de se recordar quem são os filhos do idoso, quem são os netos, irmãos, esposa, e, aprofundando-se, em sobrinhos, genros, noras, cunhados e assim por diante.

A partir do raio do conhecimento e da área da ignorância apresentados na Fig. 8, é possível montar a formatação textual presente na Fig. 9.

Dessa forma, segue-se montando um organograma das lembranças resgatadas. A padronização e organização dessas recordações permitem montar um histórico do que já foi lembrado, em que momento foi lembrado e quais pontos merecem serem recordados. 


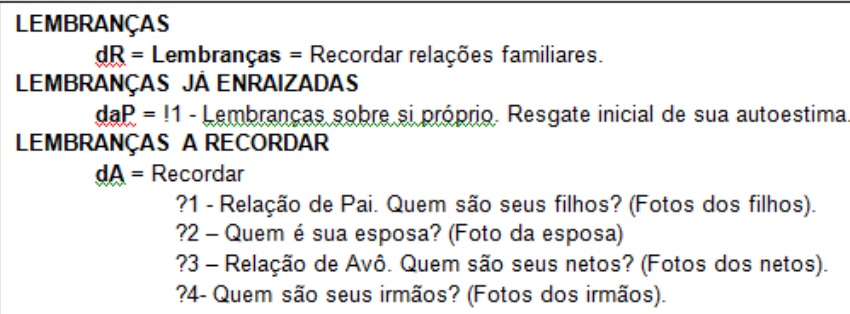

Fig. 9 - Formatação textual do raio do conhecimento e da área da ignorância - Relação Familiar.

Essa organização permite também ao cuidador verificar os momentos ou situações em que somente as informações textuais e fotografias não alcançam os resultados esperados, podendo, a partir desse ponto, ser necessário inserir novas ferramentas cognitivas, como, por exemplo, jogos com informações referentes aos membros familiares. Destaca-se que qualquer tipo de jogo deve ser trabalhado em um ambiente de meios frios, sendo importante evitar, dessa forma, o uso de computadores, animações e afins. O uso de computadores, nesse tipo de situação, pode ser para se gerar os elementos do jogo e imprimi-los.

Após o processo de recordação das lembranças em conjunto com o idoso, surge um novo questionamento.

- A partir desse momento, como fazer para que o idoso não tenha que, a cada nova recordação, ter de recordar as lembranças já trabalhadas?

Experimentações permitiram inferir uma solução singular, eficiente e efetiva, denominada Ferramenta de Memorização Permanente do Aprendizado $2^{n}$. Concluiuse, com os experimentos relacionados a essa ferramenta, que, para que um aprendizado seja fixado, é importante reforçá-lo em uma relação de $2^{n}$. Essa relação de $2^{n}$ garante que as recordações relembradas serão fixadas pelo resto da vida, isto é, ao praticá-la pode-se ter uma memorização duradoura e eficiente.

\section{FERRAMENTA DE MEMORIZAÇÃO PERMANENTE DO APRENDIZADO: $2^{\text {n }}$}

Este estudo sobre memorização, relacionado à prática de reforço $2^{n}$, foi iniciado pela verificação de que as novas informações recebidas pelo cérebro normalmente tendem a se perderem e serem esquecidas, caso não sejam reforçadas com um novo acesso em um determinado período de tempo.

Trabalhando com idosos, observou-se que, quase sempre, eles se lembravam de fatos ocorridos durante sua infância, adolescência e mocidade, e quase nada se lembravam de fatos ocorridos há dois ou três dias. Isso foi o início da inferência que direcionou a pesquisa a buscar e determinar o intervalo de tempo para se recordar e reutilizar um conhecimento no processo de memorização, para que nunca fosse esquecido.

Com base nessa observação, pode-se concluir, empiricamente, que o tempo entre reforços não é linear, o qual pode ser representado por um fator, em dias, de $2^{n}$, onde $n$ é um número Natural e $2^{n}$ representa o número em dias.

Portanto, para que uma informação nova seja memorizada e consolidada, ela 
deve ser revista no dia seguinte, isto é, em 1 dia $\left(2^{0}\right)$. Depois disso, a mesma informação deve ser revista em 2 dias $\left(2^{1}\right)$, posteriormente deve-se rever a mesma informação em 4 dias $\left(2^{2}\right)$, depois em $8\left(2^{3}\right)$ dias, em $16\left(2^{4}\right)$ dias, de mês em mês, de dois em dois meses, de quatro em quatro meses, de oito em oito meses, e assim por diante, até chegar em um ponto em que se pode dizer que a informação está praticamente consolidada, já que, em um certo momento, o fator $2^{n}$ resultaria em valores superior a algumas décadas.

Quando se segue 0 fator de memorização $2^{n}$, pode-se atestar, a uma pessoa normal e saudável, que o conhecimento não mais será perdido. Segundo Izquierdo (2010), tanto a memorização quanto a aprendizagem baseiam-se nas trocas de informações entre os neurônios transmissores de diversos setores do cérebro, promovendo, dessa forma, a troca de informação, busca e sedimentação de conhecimentos.

Quando se faz uma busca de um conhecimento, as ligações eletroquímicas das sinapses dos neurônios transmissores são reativadas e fortalecidas. Quanto maior for o número de vezes que forem utilizadas, menor será a chance das ligações eletroquímicas se enfraquecerem a tal ponto de se perder a informação.

Esse reforço no processo de sedimentação das lembranças pode ser obtido aplicando-se diferentes estratégias de repetição de objetos já trabalhados, como, por exemplo, aplicar novos Mapas de Conhecimento que recordem, na área de pre-conhecimentos, as lembranças já trabalhadas em conhecimentos anteriores.

A Fig. 10 apresenta um exemplo de aplicação da ferramenta $2^{n}$ em conjunto com funtores e raio do conhecimento e área da ignorância. Nesse exemplo, tem-se um trabalho encadeado, no qual, em um primeiro dia, o cuidador pode trabalhar com o idoso os conceitos referentes à autoestima e, no dia seguinte $\left(2^{n}+1\right)$, podem-se trabalhar as relações familiares. Diante das características peculiares de cada idoso, esse intervalo entre as aplicações da ferramenta $2^{n}$ pode ser mais espaçado, chegando a um valor confortável e adequado que não sobrecarregue o bemestar do idoso.

Tempo em dias

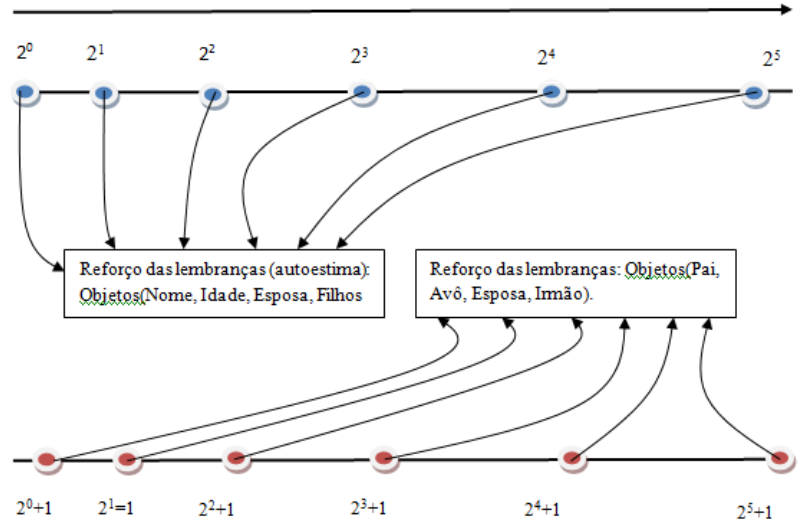

Fig. 10 - Aplicação da ferramenta $2^{n}$ em conjunto com funtores e raio do conhecimento e área da ignorância (fora de escala). 
A seção 5 apresenta um estudo de caso com as ferramentas propostas neste trabalho.

\section{ESTUDO DE CASO}

O caminho a ser seguido no resgate de um idoso, em sua cidadania, deve, primeiramente, passar pelo âmbito familiar, permitindo ao idoso o reconhecimento de si próprio, como alguém que ainda é, e não como alguém que um dia foi.

O objetivo deste estudo foi aplicar as ferramentas propostas neste trabalho em um ambiente real, e analisar os dados obtidos com meta na possibilidade de validação de resultados que representem o resgate do idoso de forma participativa ao convívio familiar e social.

Este estudo de caso utilizou uma amostra populacional de idosos, composta por 13 pessoas residentes na cidade de Araguari (MG), com faixa etária acima de 70 anos, sem nenhum problema de saúde mental (doença que impeça o raciocínio), que viva com a família ou que estejam fora da sociedade, isto é, que possuam pouco contato com as pessoas, passando boa parte do tempo isoladas/sozinhas.

Este estudo teve duração de 16 meses (o equivalente a $2^{9}$ dias), nos quais foram trabalhados 3 funtores (3 grupos de lembranças temáticas).

Cada encontro teve duração de 40 minutos. As ferramentas utilizadas nesses encontros incluíam fotografias, músicas, jogos lúdicos (em meios frios) e objetos disponibilizados por familiares que tinham relação com fatos ocorridos na vida do idoso.

Em relação aos cuidadores que participaram do estudo de caso, tem-se que para aqueles idosos que residiam com os familiares, o cuidador principal esteve representado por um filho(a) e, para os demais, o cuidador principal nem sempre esteve representado por uma pessoa fixa.

Os 3 grupos temáticos trabalhados foram:

1) Auto Reconhecimento (Autoestima): Identificação de si próprio, realçando o seu papel de indivíduo dentro da família ou do ambiente em que vive; relembrando sua idade, sua condição de esposo (a) (nos casos em que ainda possuía um companheiro(a); sua condição de pai, com a identificação de seus filhos;

2) Relações Familiares: Identificação e relação entre os filhos, os netos, os irmãos ainda presentes, relação com as atividades que cada um dos membros familiares desempenha ou desempenhou dentro da família.

3) Relação Extra Familiar: Identificação das atividades/profissão exercida pelo idoso, hábitos frequentes ao longo dos anos, jogos, passatempos e lembranças de lugares frequentados pelo idoso.

\section{DISCUSSÃO DE RESULTADOS}

Durante a aplicação das ferramentas neste estudo de caso, perceberam-se mudanças significativas entre os idosos acompanhados. O ponto principal que se destaca em primeiro plano é a receptividade por parte do idoso em participar desse tipo de projeto. Fica evidente a alegria $\mathrm{e}$ satisfação em poder exercer o contato com pessoas fora de seu círculo de convivência.

A Tabela 1 apresenta a quantidade de idosos que conseguiram, efetivamente, 
manter um valor percentual de recordações na memória até o final do estudo de caso.

Tabela 1 - Relação entre o percentual de recordações por grupos temáticos mantidos até o final do estudo de caso por número de idosos

\begin{tabular}{|c|c|c|c|}
\hline & Grupo Temático 1 & Grupo Temático 2 & Grupo Temático 3 \\
\hline $\begin{array}{l}\text { Manteve ao final do } \\
\text { estudo de caso } \\
\text { menos de } 50 \% \text { das } \\
\text { recordações } \\
\text { trabalhadas }\end{array}$ & Nenhum idoso & 2 idosos & 2 idosos \\
\hline $\begin{array}{l}\text { Manteve ao final do } \\
\text { estudo de } 50 \% \text { a } 70 \% \\
\text { das recordações } \\
\text { trabalhadas }\end{array}$ & 1 idoso & 2 idosos & 3 idosos \\
\hline $\begin{array}{l}\text { Manteve ao final do } \\
\text { estudo de caso mais } \\
\text { de } 70 \% \text { das } \\
\text { recordações } \\
\text { trabalhadas }\end{array}$ & 12 idosos & 9 idosos & 8 idosos \\
\hline
\end{tabular}

Os resultados apresentados na Tabela 1 permitem verificar que, referente ao grupo temático 1 , todos os idosos mantiveram suas lembranças e recordações sobre si mesmos (se auto conhecer novamente) até o final do estudo. Esse dado é importante porque contrasta com um cenário inicial onde a quase totalidade dos idosos mal se lembravam de quem realmente eram no início do estudo. Muitos desconheciam o nome completo e a própria idade.

Esse trabalho de recordação e memorização das lembranças permitiu que ao final do estudo, muitos idosos já possuíssem uma quantidade grande e suficiente de informações sobre si a ponto de poderem manipulá-las e de realizarem inferências com essas informações, permitindo, dessa forma, iniciar um grau de interação com os membros familiares.

O Gráfico 1 apresenta uma relação de desempenho da quantidade percentual de lembranças recordadas por grupos temáticos. Esse Gráfico permite identificar que os pontos que mais motivaram os idosos sempre estavam ligados às recordações de si mesmos, isto é, sua autoestima. Somente o grupo temático número 3 apresentou baixo percentual de recordação. A quantidade de objetos trabalhados, nesse grupo, foi muito grande, a ponto de se ter que recordar muitas vezes pontos já trabalhados. 


\section{Gráfico 1 - Relação percentual entre grupos temáticos sobre a quantidade de lembranças memorizadas até o final do estudo.}

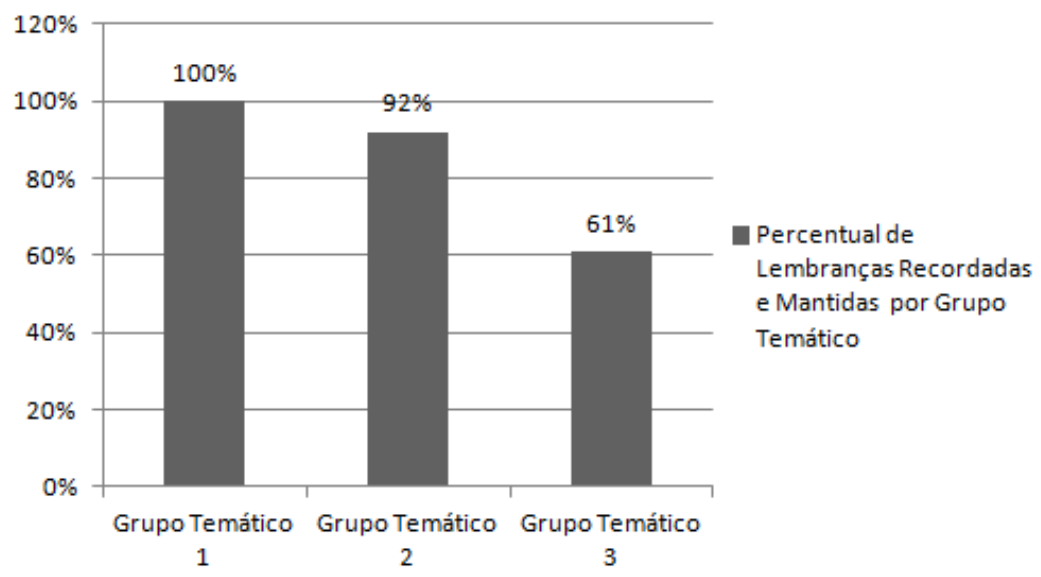

Um ponto importante nos resultados obtidos nesta pesquisa diz respeito ao estímulo aplicado ao cérebro por meio de exercícios que trabalhem a memorização e a relação entre informações. Por meio do Gráfico 2, pode-se perceber que, com o tempo, a quantidade de informações retidas pelo cérebro do idoso aumenta significativamente.

À medida que lembranças antigas são recordadas, as associações entre essas lembranças permitem evocar, de maneira rápida, um conjunto de outras lembranças com as quais tenham relação. Esse fato permitiu agilizar as atividades praticadas durante os encontros, isto é, em determinadas recordações, bastavam apenas alguns objetos ou fotografias sobre o ponto em questão.

\section{Gráfico 2 - Evolução percentual da quantidade de lembranças fixadas durante 0 estudo de caso}

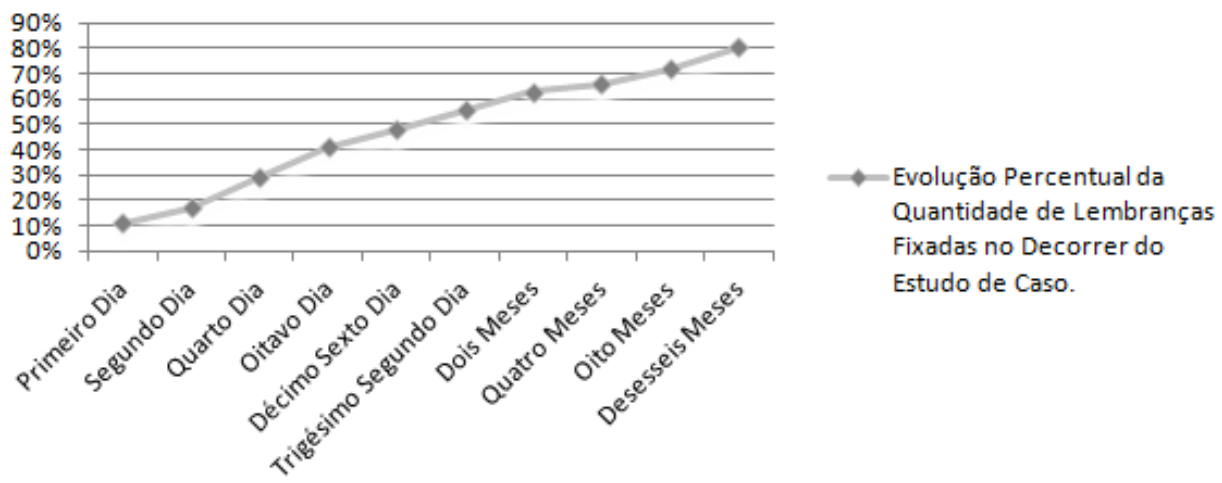

\section{CONCLUSÕES}

A expectativa de vida dos idosos aumentou significativamente na última década. Isso ocorre mais em quantidade do que em qualidade, o que se pode perceber devido ao fato de existirem poucos trabalhos que avaliam os métodos de reintegração dos idosos à família, à sociedade e ao mercado de trabalho. Muitas pesquisas focam pontualmente na identificação e tratamento de sintomas que afligem os idosos, 
principalmente aqueles decorrentes de estados emocionais que englobam a depressão, solidão e isolamento. Esses sintomas apontam pela deficiência na qualidade dessa sobrevida alcançada. Identificar e tratar esses sintomas são de grande importância, tanto nas pesquisas quanto na clínica, porém, tão ou mais importante é a adoção de novas medidas e paradigmas profiláticos que apontem alternativas que resgatem os idosos à autoestima, à família e à sociedade, o que poderia, em grande parte, evitar os sintomas decorrentes de seu isolamento social.

A decadência dos processos de memorização e cognição dos idosos são fatores que contribuem em grande parte para esse tipo de problema. Este artigo apresentou soluções e ferramentas que podem auxiliar na maximização dos processos de memorização e aprendizado, componentes fundamentais para o resgate do idoso à cidadania.

O presente estudo apresenta um conjunto de ferramentas cognitivas que podem ser utilizadas por pessoas próximas aos idosos, pessoas essas compostas por cuidadores/acompanhantes (membros familiares próximos) ou profissionais destacados a tais atividades (psicólogos, enfermeiros, terapeutas ocupacionais, outros).

Inicialmente, mostrou-se a importância de se estabelecer uma categoria mínima exigida em um processo de comunicação eficiente, fundamentada na teoria de funtores da matemática. Para a eficiência dessa comunicação, foi mostrada a importância de se estabelecer um mapeamento de objetos (elementos e conceitos) e morfismos (técnica que se aplica aos objetos) entre o cuidador e o idoso, equalizando as subcategorias do cuidador e idoso, fundamental para que o aprendizado se estabeleça.

Este artigo apresentou a ferramenta denominada raio do conhecimento e área da ignorância. Essa ferramenta assegura que o conhecimento a ser memorizado seja apresentado de forma gradativa, com o grau mínimo de dificuldade e conhecimentos necessários. Por utilizar os dois hemisférios simultaneamente no processo de memorização (hemisfério direito e esquerdo) e de lógica (hemisfério esquerdo), a ferramenta se revelou eficaz no resgate de informações presentes na memória do idoso. Esse processo de resgate se mostrou efetivo principalmente com referência à memória recente, já que o resgate de memória e conhecimentos recentes é um dos sérios problemas enfrentados pelo idoso. O processo de reforço agregado pela ferramenta denominada Memorização Permanente do Aprendizado $2^{n}$ tornou ainda mais eficiente a manutenção de informações, sejam elas recentes ou mesmo de médio e longo prazo.

Este artigo mostrou, também, que o idoso, caso não apresente problemas de saúde, como isquemia cerebral, derrames, Alzheimer, e outros que limitem o aprendizado e a memorização, é capaz de reter e resgatar informações, mesmo recentes. É muito comum se contratar um terapeuta, uma ou duas vezes por semana, para trabalhar a memória e a cognição do idoso, sendo que, geralmente, nesses atendimentos, não se costumam seguir o intervalo de tempo de $2^{n}$ proposto neste trabalho. Ao se fazer isso, nota-se uma grande dificuldade de se obter as informações desejadas, mesmo buscando-as com intervalos de tempo de alguns dias, como, por exemplo, uma semana. Isso não ocorre quando se buscam informações ocorridas na infância, adolescência e idade 
adulta do idoso. As informações muito antigas acabam por seguir ou até mesmo ultrapassar o reforço de $2^{n}$, proposto neste trabalho, de onde se conclui porque essas informações são resgatadas tão facilmente.

Ao seguir a razão $2^{n}$, resultado obtido e mostrado nesta pesquisa, as informações se preservam e ficam passíveis de serem resgatadas. Os problemas de apresentação de conceitos que exigem encadeamento lógico também obtiveram sucesso ao serem apresentados ao idoso utilizando subcategorias com o mínimo de objetos e morfismos necessários ao que se desejava transmitir, ou seja, aplicando a estratégia do raio do conhecimento e área da ignorância.

Por meio do estudo de caso, foi possível concluir a eficiência das ferramentas propostas. No corpo deste artigo, vários pontos positivos surgiram dos resultados obtidos, ressaltando que os estudos foram realizados com idosos sem problemas de saúde que comprometessem o aprendizado. Dessa forma, dever-se-á realizar novos estudos para grupos de idosos com diversos tipos de patologias mentais para que se possa determinar, a cada grupo, os ajustes que se façam necessários. Exemplo: supondo $2^{9}$, dezesseis meses, pode ser que, passado os dezesseis meses, em algumas patologias ou atraso de aprendizado, seja necessário repetir três dias seguidos a informação. Apenas novos estudos poderão responder a essa observação.

\section{AGRADECIMENTO}

Os autores agradecem à Fundação de Apoio ao Desenvolvimento do Ensino, Ciência e Tecnologia do Estado de Mato Grosso do Sul - FUNDEC, pelo auxílio financeiro à execução do trabalho.

\section{REFERÊNCIAS}

ASPERTI, A.; LONGO, G. Categories Types and Structures: An Introduction to Category Theory for the Working Computer Scientist. Massachusetts: MIT Press, 1991. Foundations of Computing Series,

BUZAN, T. BUZAN, B. The Mind Map Book: How to Use Radiant Thinking to Maximize Your Brain's Untapped Potential. New York: NY: Plume, 1996.

CALDAS, C. P., SALDANHA, A. L. A Saúde do Idoso: A Arte de Cuidar. 2. ed. Rio de Janeiro: Interciência, 2004.

IZQUIERDO, I. A Arte de Esquecer. 2. ed. Rio de Janeiro: Vieira \& Lent, 2010.

MCLUHAN, M. The Medium is the Message: An Inventory of Effects (with Quentin Fiore). New York: Bantam Books, 1967.

SARTI, C. A. Família e individualidade: um problema moderno. Texto preparado para mesa-redonda "Perspectivas de análise teórica da família", no Seminário A Família Contemporânea em Debate. Instituto de Estudos Especiais da PUC de São Paulo, outubro de 1993.

SERGER, C. A.; MILLER, E. K. Category Learning in the Brain. Annual Review of Neuroscience, v. 33, p. 203-219, 2010.

VERAS, R. P. A longevidade da população desafios e conquistas. Serviço Social \& Sociedade, São Paulo, v. 24, n. 75 especial, p. 5-18, set. 2003.

WORLD HEALTH ORGANIZATION. Life expectancy at birth: Both sexes: 2011. [Geneve]: WHO, 2013. Disponível em: http://gamapserver.who.int/gho/interactive c harts/mbd/life expectancy/atlas.html. Acesso em: 28 ago. 2013. 